\title{
Regulation of Emotional, Marital Satisfaction and Marital Lifestyle of Fertile and Infertile
}

\author{
Abolfazl Azizi ${ }^{1}$ \\ ${ }^{1}$ Department of Psychology, Islamic Azad University, Iran \\ Correspondence: Abolfazl Azizi, MSc in General Psychology at Islamic Azad University,Department of Psychology, \\ Faculty of Humanities, Shahrekord Branch, Islamic Azad University, Shahrekord, Iran.
}

\author{
Received: December 2, 2017 Accepted: December 29, 2017 Online Published: January 3, 2018 \\ doi:10.5539/res.v10n1p14 \\ URL: https://doi.org/10.5539/res.v10n1p14
}

\begin{abstract}
The purpose of this present study is investigating of relationship and compare between emotion regulation, marital satisfaction and lifestyle of the fertile and infertile couples in Isfahan. The sample consisted of two groups of 200 people in fertile and infertile couples in Isfahan who were selected based on availability. To collect information was used from questionnaires lifestyle, marital satisfaction and cognitive emotion regulation. The results showed that lifestyle and marital satisfaction in fertile and infertile no significant difference in cognitive emotion regulation fertile and infertile couples, but there is a significant difference. Infertile couples have lower cognitive emotion regulation. As well as lifestyle and marital satisfaction in fertile and infertile couples have a significant positive relationship that the relationship is stronger for infertile couples. Lifestyle and cognitive emotion regulation, marital significant negative relationship with cognitive emotion regulation has a significant positive relationship between fertile and infertile couples $17.7 \%$ of fertile couple's marital satisfaction and cognitive emotion regulation with fertile couples to explain them is not a predictor of marital satisfaction. But lifestyle $22.6 \%$ of infertile couples infertile couples marital satisfaction and cognitive emotion regulation in the first and $7.4 \%$ of infertile couples to predict marital satisfaction, Therefore, it is essential that interventions for infertile couples to be cognitive of the training set to handle the excitement of infertility and prevent problems related to it.
\end{abstract}

Keywords: Emotion Regulation, Marital satisfaction, Lifestyle, Fertile and Infertile couples, Isfahan

\section{Introduction}

Family is introduced an institution or social institution that is caused men and women marriage. Including aspects of human social life, Healthy and productive interaction between humans and to establish the same type of love and intimacy and empathy expressed to each other. Family is a place for satisfy of different needs such as physical and intellectual and emotional. Knowing and understanding how to satisfy their biological and psychological needs and processing technique to understand the biological and psychological tendencies is undeniable necessity. A person's marital satisfaction, as satisfaction is the family and Family satisfactions in the sense of satisfaction was unattractively and as a result, facilitate the growth and development of material and spiritual progress of society (Edalati \& Radzuan 2011). One of the functions of the family that marital satisfaction is strongly influenced by the childbearing. Research shows that more than $11 \%$ of women as soon as they understand their fertility are a problem, their confidence decreases. At the same time, one of the reasons for infertility in women is stress role of motherhood; the most important role of women in most societies is considered an adult. Also, a lot of tests and treatment of infertility on women, which will only increase the psychological pressure, will be greater. These factors make infertile women, to know more responsible in infertility problem (Gibson, 2011). The study indicates that infertile women are more anxious and depressed than fertile women (Berek, 2012 \& Karami, 2011). Welfare management and proper regulation of emotions is one of the foundations for well-being and psychological health. Conscious or unconscious emotion regulation processes (dealing and controlled) it encompasses, that to increase maintaining or reducing one or more components of emotional response is used. In other words, the process repeatedly ways through which people experience and express their excitement under pressure control. These strategies are such as repression, inhibition and cognitive assessment. Studies have shown that emotion regulation optimal with function properly in cognitive homework has linked adults. Knowledge of emotional experience is an essential prerequisite for emotional regulation and decision making about appropriate behavior. Emotional awareness to allow person of one hand driving characteristics and on other hand pay attention to your emotional symptoms and to recognition and classify of situations and feelings. The process of choice and use of effective self-regulation strategies provide. Regulation and emotional control are at least two important benefits: for physical and mental health is very helpful and is 
an important social skill. Emotion regulation by identifying inextricably intertwined with human life, and helps. For example, when faced with threatening or stressful events, and have dominion over them, and not overwhelmed in emotions (Garnefski, Keraj, Spinhavn, 2011). A lot of emotion regulation processes is common between human. But it seems that each person tends to use for certain models. In these models, emotion regulation strategies and it cognitive scope is called cognitive emotion regulation strategies. For example, when each of us is faced with the problem and we are sad, we set out frustration in different ways. As a result, to used different emotional response pattern. You may blame them or others, be considered catastrophic situation, passively difficult to accept, Wash sink in our thoughts, our mind focused on other goals, we will deal with pleasant thoughts, to find positive concepts for problem or seek some plan to fix the problem(Salehi and et al, 2011). Despite the emotional similarities between humans is expected, a pattern that each person uses to regulate emotions, to be followed different emotional results. In this case Garnefski and keraj (2006) showed that use some strategies such as self-blame, rumination and catastrophic read and partly blaming others for adults with mental disorders are more common. Other researchers including Mack Gee, Wolf, Nolen Haksma, Mack Bride and Larso and Olson (2006). However, the ability to control one's emotions is one of the most important features that must be learned. Emotional regulation as the beginning of the process, maintain, modify or alter the incidence, severity or the continuity of inner feelings and emotions associated with the process of socio-psychological, physical person to accomplish the goals defined (Vimez \& pina, 2010). Marital satisfaction is an overall assessment of the person's current marital relationship or romantic relationship. Marital satisfaction may be a reflection of the happiness of being satisfied by a combination of marital or marital relationship by many-specific factors. Marital satisfaction can be considered as a psychological situation that does not occur spontaneously, but requires the efforts of both couples. Especially in light of the initial, very unstable marital satisfaction and relations are at greatest risk (Afzali, Nabipuor, Kimiyaei, Ahmadi, 2014). Marital Satisfaction is linked to happiness and joy of relationships between couples. Marital satisfaction suggests that, marital satisfaction means having a good sense of marriage (Kaplan \& Madoks, 2002). Marital satisfaction in marriage is a personal experience that only self-pleasures in response to the marital relationship may be assessed. They believe that marital satisfaction is related to people's expectations. Marriage is considered important in all societies and having a successful marriage and ideal for just about everyone is a major goal (Mirez, Madatil, Tingle, 2005). A variety of factors affect the strength and durability of the family, including the couple's consent (Atari, Abbasi, Mehradizadeh, 2007). Anything is more important is your marriage and family life is marriage and intimacy and marital satisfaction. Marital satisfaction on many aspects of individual and social life affects couples and family's cornerstone is performance. Marital satisfaction is a process that occurs during of the husband and wife life. This requires compliance tastes, personality traits, establishing rules of conduct and formation patterns of interaction. Therefore, marital satisfaction between men and women is evolution process.(Ahmadi, Fathi, Ashtiyani, Arabnia, 2007). Marital satisfaction is a multidimensional concept that different factors involved extensive and effective. In this sense, a large part of his research has been published about marital (Kadir, Dasilva, Prins, Khan, 2005). Several factors effects on satisfaction marriage including personality (Shenorman, Kerok, 2011) and educational and social class (Jalili, 1997 \& Moradi, 2007) religious beliefs (Arafi, 2007 \& Hashemi,Golshan Abadi,2007) Finance, interest, attention, support and understanding spouse employment of women, number of children (Tork, 2007) and etc. Some personality traits and mental disorders tensions and conflicts in pregnancy and infertility problems among couples increase and threatening the continuation of marital life. Studies show consistency and marital satisfaction, the greatest impact on personality traits couple receives and the relationship between psychological characteristics and personality with intent to divorce and marital conflict is mutual (Fisher \& mack nelly, 2012). Part of the problem stems from differences between spouses is marital relationship. But something that is important is the reaction of couples having problems and differences. So that the use of destructive methods to avoid and solve problems such as fights, most couples would only detached and intimate relationship is loosening. This is more in the first year of marriage. Because of failing spouses resolving difficulties for discord and divorces is highest talent (Kanoy, 2002). For this stage of marriage adjustment phase, synchronized with each other and your spouse should comply with the wishes and needs of the other side. On the other hand this point, one of the stages of the life cycle that couples can experience the greatest satisfaction with one another (Kelading, 2005). So enjoy the lifestyle work to solve problems can be satisfactorily marriage and lead to success. In couples therapy approaches each with specific explanation, it confirms. Integrative behavioral couple therapy suggests that the happiest and healthiest always even couples also face the disagreements and differences that are natural and inevitable. So the problem due to the differences and conflicts between couples not occur, but because of the way by which couples respond to the inevitable differences caused (Khamseh, 2007). New findings have shown that sexual knowledge and attitudes with different aspects of behavior, performance, satisfaction and sexual health are related. Training to improve marital sexual knowledge while improving sexual dysfunction, sexual satisfaction and marital satisfaction Women with perfect physical health, mental and emotional foundations of a strong and healthy family life with happiness. However, the problems of sexual desire, sexual arousal and orgasm, as well as other aspects of sexual function among women ages $11 \%$ to $21 \%$, reported and this enjoyable sexual relationship and sexual satisfaction has been difficult. Marital problems are influenced by multiple variables biological, 
social, cultural, family and the relationship which shows that psychological interventions plays an important role in marital problems. Strengthening the foundation of the family and families by increasing awareness of sexual health promotion and improvement of sexual relationships and promote awareness level of quality performance marital sex, marital satisfaction and prevent a divorce rate is increasing. Training sexual relations, the principles of marriage, the importance of sexuality, desires and normal and abnormal sexual behavior, sex and culture, conventional sexual behavior, sexual religioned and secular attitudes, women false beliefs about sex, physical evidence of sexual intercourse, sexual health, sexual differences between men and women, sexual knowledge, menstrual characteristics and its effect on sexual relationship, the sexual response cycle, symptoms and types of orgasm in men and women, style, marriage and sexual behavior, marital sexual positions, variety of male and female sexual disorders and how to treat them, beliefs, sexual dysfunction, sexual myth, solutions about sexual health, etc. (Derkhshan, 2014). So lowering marital dissatisfaction and its complications and prevention of this phenomenon in an infertile couples and infertile couples, marital satisfaction is of utmost importance. Provide effective way to handle marital couples according to personality traits, providing a secure environment combined with understanding, proper communication and strengthen relationships. With increasing marital satisfaction can be mental health of couples married life, durability, stability of the family, settle disputes and promote the health of family members and helped marital empowerment. Hence, this article seeks to investigate that whether cognitive emotion regulation, marital satisfaction and Fertility and Infertility marital lifestyle of Isfahan is different? Whether Cognitive emotion regulation, marital satisfaction has relationship with Fertility and Infertility lifestyle marital of Isfahan?

\section{Research Method}

This study aims to compare and analyze the relationship between lifestyle and emotional adjustment and marital satisfaction in fertile and infertile couples of Isfahan. Therefore, The descriptive research method (in terms of the research team evaluated the situation and the current situation is no manipulation) because the relationship between marital satisfaction between fertile and infertile and correlation (considering the relationship between the variables of the study will measure) and since, both fertile and infertile compares is the causal-comparative. The study sample consisted of all fertile couples and infertile couples being treated for infertility treatment centers in Isfahan at 1394 to 1395 year are presented. To determine the sample size by Morgan table (1970) is used. Calculations based on this table for fertile population, the population sample is 200 couples and the sample size of infertile is 200 couples and each sample was selected by convenience sampling method. Measuring instrument in this study is three questionnaires were used as follows:

\subsection{Enrich Marital Satisfaction Questionnaire}

Enrich marital satisfaction questionnaire, by Olson, Fournier and Drankman (Sanaei, 2001). In America to assess potential problem areas or identify areas of strength and has built a fruitful partnership. Marital Satisfaction Questionnaire has several general components that include mood and personality traits couples and express emotions has closed 47 questions for the whole five-item Likert (Totally agree, agree, neither agree, nor disagree, disagree, strongly disagree) That the score respectively is (4-3-2-1-0) awarded to them. Enrich questionnaire in Iran by Soleimanian (1992) The Short Form 47 questions made. Validity and reliability of the questionnaire was calculated by Soleimanian. Validity of the questionnaire with family adjustment questionnaire, respectively 0/86 and 0/92 (All at 0/05 were significant) have earned the reputation indicates it is acceptable and its reliability using Cronbach's alpha was calculated 0/95. In the present study, the coefficients of marital satisfaction questionnaire reliability was calculated using Cronbach's alpha and split-half, which respectively is 0/90 and 0/90 Which shows the reliability coefficients of the questionnaire is desirable.

\subsection{Granefski Cognitive Emotion Regulation Questionnaire}

Cognitive emotion regulation questionnaire by Granefski and colleagues (2001) have been developed, this questionnaire is a multidimensional questionnaire and a self-report instrument that has 36 articles and has special form for children and adults. Emotion regulation Scale cognitive strategies blame, acceptance, rumination, positive refocusing, refocus on planning, positive reappraisal, perspective, ideas, and blame others assess the disaster. Granefski and colleagues have reported good reliability and validity for the questionnaire. The questionnaire contains 36 questions graded score of five (always or never). All four questions to evaluate a factor. A total of nine factors as, Self-blame, blame others, catastrophic out, rumination, refocus on planning acceptance, positive focus and gives positive assessment to evaluate. Persian version of this scale by Samani and Jokar (1386) has been validated. In this questionnaire, the person is asked to react in the face of a threatening experience and that recently have experienced stressful life events by answering 5 questions to evaluate strategies to control and emotion regulation does not specify. Among the most common cognitive emotion regulation strategies in the face of adverse conditions including Blame yourself, blame others, rumination as catastrophic development prospects, positive refocusing our positive evaluation, acceptance, planning.(Samani,Sadeghi,2006). 


\subsection{Lifestyle Questionnaire}

Life Style Questionnaire (LSQ) is a multi-dimensional tool that explores the lifestyle of people (mostly in terms of health). The questionnaire has 10 sub-scales that are included: Health, sports and fitness, weight management and nutrition, disease prevention, mental health, mental health, social health, avoid drugs and narcotics, environmental health and prevention of accidents. In fact, by weighing the scales can be concluded about a person's lifestyle. The questionnaire has 70 questions that evaluate different aspects of life style (health, sports and fitness, weight management and nutrition, disease prevention, mental health, spiritual health, social health, avoid drugs and narcotics, accident prevention, health and environment).

\section{Procedure of Research}

After preparation of the questionnaire was referred to Isfahan infertility treatment centers and questionnaires were provided to couples who were referred for treatment. We clarify aim of this research for infertile couples were asked to voluntarily and anonymously to answer questions. For fertile couples also chosen couples which are more similar to infertile couples in terms of age, duration of marriage and academic study, and then data for analysis was prepared.

3-Findings:

Table 1. Mean and standard deviation scores of lifestyle and its components in fertile and infertile groups

\begin{tabular}{|c|c|c|c|}
\hline Infertile & Fertile & Index & Variable \\
\hline $2 / 71$ & $2 / 88$ & Average & \multirow[t]{2}{*}{ Physical health } \\
\hline $0 / 43$ & $0 / 49$ & Standard deviation & \\
\hline $2 / 36$ & $2 / 68$ & Average & \multirow[t]{2}{*}{ Sports and fitness } \\
\hline $0 / 60$ & $0 / 66$ & Standard deviation & \\
\hline $2 / 50$ & $2 / 70$ & Average & \multirow[t]{2}{*}{ Weight control and nutrition } \\
\hline $0 / 60$ & 0.53 & Standard deviation & \\
\hline $3 / 07$ & $2 / 94$ & Average & \multirow[t]{2}{*}{ Disease Prevention } \\
\hline $0 / 51$ & $0 / 57$ & Standard deviation & \\
\hline $2 / 88$ & $2 / 90$ & Average & \multirow[t]{2}{*}{ Mental health } \\
\hline $0 / 58$ & $0 / 54$ & Standard deviation & \\
\hline $3 / 08$ & $2 / 94$ & Average & \multirow[t]{2}{*}{ Spiritual health } \\
\hline $0 / 59$ & $0 / 67$ & Standard deviation & \\
\hline 3 & $2 / 99$ & Average & \multirow[t]{2}{*}{ Social health } \\
\hline $0 / 50$ & $0 / 57$ & Standard deviation & \\
\hline $3 / 06$ & $2 / 88$ & Average & \multirow[t]{2}{*}{ Avoid OF pain and drugs } \\
\hline $0 / 74$ & $0 / 74$ & Standard deviation & \\
\hline $2 / 94$ & $2 / 77$ & Average & \multirow[t]{2}{*}{ Prevent of accidents } \\
\hline $0 / 56$ & $0 / 66$ & Standard deviation & \\
\hline $2 / 86$ & $2 / 85$ & Average & \multirow[t]{2}{*}{ Environmental health } \\
\hline $0 / 58$ & $0 / 65$ & Standard deviation & \\
\hline $2 / 84$ & $2 / 85$ & Average & \multirow[t]{2}{*}{ life style } \\
\hline $0 / 33$ & $0 / 65$ & Standard deviation & \\
\hline
\end{tabular}

Table 1 shows the mean and standard deviation of the changing lifestyle and its components in infertile and fertile groups are close together. 
Table 2. Descriptive statistics table cognitive emotion regulation score and its components in fertile and infertile groups

\begin{tabular}{|c|c|c|c|}
\hline Infertile & Fertile & Index & Variable \\
\hline $11 / 70$ & $10 / 75$ & Average & \multirow{2}{*}{ Self-Blame } \\
\hline $3 / 42$ & $2 / 65$ & Standard deviation & \\
\hline $13 / 16$ & $11 / 23$ & Average & \multirow{2}{*}{ Reception } \\
\hline $3 / 60$ & $2 / 54$ & Standard deviation & \\
\hline $14 / 20$ & $12 / 05$ & Average & \multirow[t]{2}{*}{ Reception } \\
\hline $3 / 17$ & $3 / 03$ & Standard deviation & \\
\hline $14 / 82$ & $12 / 63$ & Average & \multirow[t]{2}{*}{ Positive refocusing } \\
\hline $3 / 23$ & $3 / 20$ & Standard deviation & \\
\hline $15 / 22$ & $13 / 05$ & Average & \multirow{2}{*}{ Refocus on planning } \\
\hline $3 / 07$ & $3 / 25$ & Standard deviation & \\
\hline $14 / 70$ & $12 / 48$ & Average & \multirow[b]{2}{*}{ Positive reappraisal } \\
\hline $3 / 12$ & $3 / 08$ & Standard deviation & \\
\hline $13 / 85$ & $11 / 79$ & Average & \multirow[t]{2}{*}{ Perspective-taking } \\
\hline $2 / 95$ & $3 / 15$ & Standard deviation & \\
\hline $12 / 08$ & $11 / 54$ & Average & \multirow{2}{*}{ Catastrophizing } \\
\hline 4 & $3 / 15$ & Standard deviation & \\
\hline $10 / 72$ & $10 / 40$ & Average & \multirow[t]{2}{*}{ Blame others } \\
\hline $3 / 171$ & $2 / 97$ & Standard deviation & \\
\hline $120 / 47$ & $105 / 93$ & Average & \multirow[t]{2}{*}{ Cognitive emotion regulation } \\
\hline $19 / 78$ & $15 / 90$ & Standard deviation & \\
\hline
\end{tabular}

Table 2 shows the mean and standard deviation of variable cognitive emotion regulation and its components in the infertile group is most fertile group. 
Table 3. Mean and standard deviation of marital satisfaction and its components in fertile and infertile groups

\begin{tabular}{|c|c|c|c|}
\hline Infertile & Fertile & Index & Variable \\
\hline $3 / 89$ & $3 / 64$ & Average & \multirow[t]{2}{*}{ Contractor responsible } \\
\hline $0 / 81$ & $0 / 89$ & Standard deviation & \\
\hline $3 / 35$ & $3 / 32$ & Average & \multirow[t]{2}{*}{ Marital Satisfaction } \\
\hline $0 / 63$ & $0 / 67$ & Standard deviation & \\
\hline $2 / 82$ & $2 / 96$ & Average & \multirow[t]{2}{*}{ Personality } \\
\hline $0 / 90$ & $0 / 78$ & Standard deviation & \\
\hline $3 / 01$ & $3 / 16$ & Average & \multirow[t]{2}{*}{ Marital relationship } \\
\hline $0 / 81$ & $0 / 75$ & Standard deviation & \\
\hline $2 / 93$ & $3 / 07$ & Average & \multirow[t]{2}{*}{ Conflict resolution } \\
\hline $0 / 60$ & $0 / 56$ & Standard deviation & \\
\hline $3 / 24$ & $3 / 39$ & Average & \multirow[t]{2}{*}{ Financial Oversight } \\
\hline $0 / 94$ & $0 / 79$ & Standard deviation & \\
\hline $3 / 24$ & $3 / 21$ & Average & \multirow[t]{2}{*}{ Activities related to leisure } \\
\hline 0.83 & $0 / 67$ & Standard deviation & \\
\hline $3 / 42$ & $3 / 23$ & Average & \multirow[t]{2}{*}{ Sexual relationship } \\
\hline $0 / 72$ & $0 / 63$ & Standard deviation & \\
\hline $3 / 02$ & $3 / 14$ & Average & \multirow[t]{2}{*}{ Marriage and children } \\
\hline $0 / 68$ & $0 / 69$ & Standard deviation & \\
\hline $3 / 15$ & $3 / 21$ & Average & \multirow[t]{2}{*}{ Relatives and friends } \\
\hline $0 / 82$ & $0 / 69$ & Standard deviation & \\
\hline $3 / 99$ & $3 / 35$ & Average & \multirow[t]{2}{*}{ Roles related to gender equality } \\
\hline $0 / 96$ & $0 / 93$ & Standard deviation & \\
\hline $3 / 04$ & $3 / 05$ & Average & \multirow[b]{2}{*}{ Ideological orientation } \\
\hline $0 / 84$ & $0 / 88$ & Standard deviation & \\
\hline $3 / 21$ & $3 / 23$ & Average & \multirow[t]{2}{*}{ Sexual satisfaction (total) } \\
\hline $0 / 46$ & $0 / 48$ & Standard deviation & \\
\hline
\end{tabular}

Table 3 shows the mean and standard deviation of marital satisfaction and its components in infertile and fertile groups are near together.

Table 4. Independent t-test results lifestyle fertile and infertile groups

\begin{tabular}{|c|c|c|c|c|c|c|c|c|}
\hline sig & $\mathrm{df}$ & $\mathrm{t}$ & sig & $\mathrm{F}$ & Standard deviation & Average & & Variables \\
\hline $0 / 816$ & 398 & $0 / 233$ & \multirow[t]{2}{*}{$0 / 046$} & \multirow[t]{2}{*}{$3 / 996$} & $0 / 37$ & $2 / 85$ & Fertile & \multirow[t]{2}{*}{ Life style } \\
\hline $0 / 816$ & $393 / 47$ & $0 / 233$ & & & $0 / 33$ & $2 / 84$ & Infertile & \\
\hline
\end{tabular}

Table 4 shows that the fertile and infertile couple's lifestyle couples are not significantly different. In other words fertile and infertile couple's lifestyle couples are alike. 
Table 5. Shows the results of independent $t$ test cognitive emotion regulation infertile and fertile groups

\begin{tabular}{|c|c|c|c|c|c|c|c|c|}
\hline sig & $\mathrm{df}$ & $\mathrm{t}$ & sig & $\mathrm{F}$ & $\begin{array}{l}\text { Standard } \\
\text { deviation }\end{array}$ & Average & & Variables \\
\hline $0 / 0001$ & 398 & $-8 / 09$ & \multirow[t]{2}{*}{$0 / 0001$} & \multirow[t]{2}{*}{$19 / 601$} & $15 / 90$ & $105 / 93$ & Fertile & \multirow{2}{*}{$\begin{array}{l}\text { Cognitive emotion } \\
\text { regulation }\end{array}$} \\
\hline $0 / 0001$ & $380 / 39$ & $-8 / 09$ & & & $19 / 78$ & $120 / 47$ & Infertile & \\
\hline
\end{tabular}

Table 5 shows that cognitive emotion regulation fertile couples and infertile couples have a significant difference. Means comparison showed that infertile couples have lower cognitive emotion regulation.

Table 6. Independent t-test results marital satisfaction in fertile and infertile groups

\begin{tabular}{|c|c|c|c|c|c|c|c|c|}
\hline sig & $\mathrm{df}$ & $\mathrm{t}$ & $\operatorname{sig}$ & $\mathrm{F}$ & $\begin{array}{l}\text { Standard } \\
\text { deviation }\end{array}$ & Average & & Variables \\
\hline $0 / 686$ & 398 & $0 / 404$ & \multirow[t]{2}{*}{$0 / 774$} & \multirow[t]{2}{*}{$0 / 084$} & $0 / 48$ & $3 / 23$ & Fertile & \multirow{2}{*}{$\begin{array}{c}\text { Marital } \\
\text { Satisfaction }\end{array}$} \\
\hline $0 / 686$ & $397 / 46$ & $0 / 404$ & & & $0 / 46$ & $3 / 21$ & Infertile & \\
\hline
\end{tabular}

Table 6 shows that marital satisfaction in fertile and infertile couples are not significantly different. In other words, marital satisfaction in fertile and infertile couples is alike.

Table 7. Shows the correlation coefficient lifestyle marital satisfaction in infertile and fertile groups

\begin{tabular}{|c|c|c|c|}
\hline Marital Satisfaction & Indexes & Variables & Groups \\
\hline $0 / 420$ & correlation coefficient & Lifestyle & Fertile \\
\cline { 1 - 2 } $0 / 0001$ & Significance level & & \\
\hline $0 / 476$ & correlation coefficient & Lifestyle & Infertile \\
\cline { 1 - 2 } $0 / 0001$ & Significance level & & \\
\hline
\end{tabular}

Table 7 shows that marital satisfaction in fertile and infertile couples a significant positive relationship $(\mathrm{r}=0 / 420)$ with lifestyle $(\mathrm{r}=0 / 476)$ for infertile couples is stronger. In other words, marital satisfaction in fertile and infertile couples with lifestyle improvement increases.

Table 8. Correlation of cognitive emotion regulation and lifestyle in fertile and infertile groups

\begin{tabular}{|c|c|c|c|}
\hline Lifestyle & Indexes & Variables & Groups \\
\hline $0 / 333$ & correlation coefficient & Cognitive emotion regulation & Fertile \\
\cline { 1 - 2 } $0 / 0001$ & Significance level & & \\
\hline $0 / 208$ & correlation coefficient & Cognitive emotion regulation & Infertile \\
\hline $0 / 0001$ & Significance level & & \\
\hline
\end{tabular}

Table 8 shows that a significant positive relationship between cognitive emotion regulation fertile couples ( $\mathrm{r}=0 / 333)$ has relationship with Lifestyle but this relationship Is negative for infertile couples ( $\mathrm{r}=-0 / 208)$. In other words, by increasing cognitive adjust their lifestyle to reduce the infertile couples. 
Table 9. Cognitive emotion regulation correlation with marital satisfaction in infertile and fertile groups

\begin{tabular}{|c|c|c|c|}
\hline Lifestyle & Indexes & Variables & Groups \\
\hline $0 / 132$ & correlation coefficient & Cognitive emotion regulation & Fertile \\
\cline { 1 - 2 } $0 / 062$ & Significance level & & \\
\hline$-0 / 248$ & correlation coefficient & Cognitive emotion regulation & Infertile \\
\cline { 1 - 2 } $0 / 0001$ & Significance level & & \\
\hline
\end{tabular}

Table 9 shows that a significant positive relationship between cognitive emotion regulation fertile couples ( $\mathrm{r}=0 / 420)$ with marital satisfaction. But this relationship $(\mathrm{r}=0 / 420)$ for infertile couples is negative. In other words, by increasing cognitive adjust their lifestyle to reduce the infertile couples.

Table 10. Summarizes the results predicted marital satisfaction in infertile and fertile groups based on variables

\begin{tabular}{|c|c|c|c|c|c|c|c|c|c|c|}
\hline \multirow{2}{*}{ Durbin-Watson } & \multicolumn{5}{|c|}{ Statistics Change } & \multirow{2}{*}{} & & & & \\
\cline { 2 - 10 } & Sig. & df2 & df1 & $\mathrm{F}$ & $\mathrm{R}^{2}$ & $\mathrm{R}^{2}$ & $\mathrm{R}^{2}$ & $\mathrm{R}$ & Model & Groups \\
\hline $1 / 443$ & $0 / 0001$ & 198 & 1 & $4 / 42$ & $177 / 0$ & $172 / 0$ & $177 / 0$ & $420 / 0$ & Lifestyle & Fertile \\
\hline & $0001 / 0$ & 198 & 1 & $9 / 57$ & $226 / 0$ & $223 / 0$ & $226 / 0$ & $476 / 0$ & Lifestyle & Infertile \\
\hline $507 / 1$ & $0001 / 0$ & 197 & 1 & $7 / 12$ & $047 / 0$ & $266 / 0$ & $273 / 0$ & $523 / 0$ & & \\
\hline
\end{tabular}

Table 10 shows that $17.7 \%$ of fertile couples lifestyle fertile couples to explain marital satisfaction and cognitive emotion regulation predictors of marital satisfaction, but they are not infertile couple's 22/6\% lifestyle percent of infertile couples in marital satisfaction once the first and $4.7 \%$ of infertile couples marital satisfaction and cognitive emotion regulation to predict.

Table 11. Coefficients predicted marital satisfaction in infertile and fertile groups based on variables

\begin{tabular}{|c|c|c|c|c|c|c|c|}
\hline \multirow[b]{2}{*}{ Sig. } & \multirow[b]{2}{*}{$\mathrm{t}$} & \multirow{2}{*}{$\begin{array}{c}\begin{array}{c}\text { Standardized } \\
\text { coefficients }\end{array} \\
\text { Beta }\end{array}$} & \multicolumn{2}{|c|}{$\begin{array}{l}\text { Not standardized } \\
\text { coefficients }\end{array}$} & & \multirow[b]{2}{*}{ Model } & \multirow[b]{2}{*}{ Groups } \\
\hline & & & Std. Error & B & & & \\
\hline $0 / 0001$ & $6 / 89$ & & $0 / 242$ & $1 / 66$ & Fixed & \multirow[t]{2}{*}{1} & \multirow[t]{2}{*}{ Fertile } \\
\hline $0 / 0001$ & $6 / 51$ & $0 / 420$ & $0 / 480$ & $0 / 54$ & Lifestyle & & \\
\hline $0 / 0001$ & $5 / 25$ & & $0 / 251$ & $31 / 1$ & Fixed & \multirow[t]{2}{*}{1} & \multirow{5}{*}{ Groups } \\
\hline $0 / 0001$ & $7 / 61$ & $0 / 476$ & $0 / 780$ & $0 / 66$ & Lifestyle & & \\
\hline $0 / 0001$ & $6 / 38$ & & $0 / 334$ & $2 / 13$ & Fixed & \multirow[t]{3}{*}{2} & \\
\hline $0 / 0001$ & $6 / 92$ & $0 / 430$ & $0 / 087$ & $0 / 60$ & Lifestyle & & \\
\hline $0 / 0001$ & $-3 / 57$ & $-0 / 222$ & 0/0001 & $-0 / 005$ & $\begin{array}{l}\text { Cognitive emotion } \\
\text { regulation }\end{array}$ & & \\
\hline
\end{tabular}

Table 11 shows that a beta coefficient lifestyle fertile couple is $0 / 420$. Which means that for every one unit increase in lifestyle is $0 / 420$ to increase marital satisfaction. Beta coefficient lifestyle is infertile couples $0 / 476$. Which means that for every one unit increase in lifestyle caused increase $0 / 476$ in marital satisfaction. And beta coefficient of cognitive emotion regulation is $-0 / 222$, that for every increase of one unit in marital satisfaction decreases $0 / 222$ cognitive emotion regulation. 


\section{Discussion and Conclusion}

The results showed no significant differences in lifestyle couples of fertile and infertile, In other words fertile and infertile lifestyle couples is alike. This finding is consistent with Abzang research results (2007). Explanation of this finding is that in fertile and infertile couples lifestyle is such that other positive aspects of married life including economic, social, science and culture and advancing the goals of the couple's infertility lifestyle they could not be more different than fertile couples. There are so many factors that can positively or negatively directly or indirectly effect on lifestyle and infertility cannot to be a destructive factor in their lifestyle. The results showed that cognitive emotion regulation in fertile couples and infertile couples have a significant difference. Means comparison showed that infertile couples have lower cognitive emotion regulation. This finding is consistent with Karimi results study (2007) aligned. He has shown that treatment of emotional regulation difficulties, significant impacts on various areas that included emotional adjustment and marital satisfaction and increase confidence in the ability to regulate emotional couple. Explanation of this finding is that infertile couples if better use of cognitive emotion regulation strategies can be used with problems including infertility consequences. The results showed that marital satisfaction in fertile and infertile couples are not significantly different. In other words, marital satisfaction in fertile and infertile couples is alike. This finding is consistent with results Yousefi and Sohrab (2011) and Roshan and et al (2013). Marital quality is affected by the level of satisfaction and adjustment spouses of each other the family functions as well be done if an important role in strengthening families is the couples' life and stability of the system.

The results showed that marital satisfaction in fertile and infertile couples a significant positive relationship ( $\mathrm{r}=0.420)$ with lifestyle that this relationship(r=0/476) for infertile couples is stronger. In other words, marital satisfaction in fertile and infertile couples with lifestyle improvement increases. This finding is consistent with results Shroniko (2009) aligned. Couples who have flexibility, adaptability and higher correlation of marital satisfaction and similarities of Couples in terms of personality traits, beliefs and lifestyle on marital satisfaction have a positive effect. The results showed a significant positive correlation between cognitive emotion regulation fertile couples ( $\mathrm{r}=0 / 333)$ with life style. But this relationship(r=-0/208) for infertile couples is negative. In other words, by increasing cognitive adjust their lifestyle to reduce the infertile couples. This finding is consistent with results of ardakani and colleagues study (2011) aligned. Explanation of this finding is that lack of attention to emotional disorders and infertile couples, infertility secondary symptoms (problem in interpersonal relationships, decreased interest in sexual and social activities, anxiety, stress, inhibition, shyness and hostility) creating a vicious cycle that reduces the risk of infertility treatment. So with to help infertile couples in the use of cognitive emotion regulation strategies such as frustration, feelings of worthlessness and inadequacy, anxiety can be to change negative beliefs about themselves and helped many other psychological problems. The results showed a significant positive correlation between cognitive emotion regulation fertile couples $(\mathrm{r}=0 / 132)$ with Marital satisfaction. But this relationship $(\mathrm{r}=-0 / 248)$ is negative for infertile couples. In other words, by increasing cognitive adjust their lifestyle to reduce the infertile couples. This finding is consistent with Ayat studies (2005), Ylsma and Sherlin (2003) and Patrice et al (2007) aligned. Explanation of this finding is that couples, especially couple's infertile positive cognitive emotion regulation strategies more they use, have more marital satisfaction. In other words, couples who have higher cognitive set of positive strategies to conclude that capability in dealing with problems and changes related to their relationship and therefore experience higher marital satisfaction. The results showed that $17.7 \%$ of fertile couples lifestyle fertile couples to explain marital satisfaction. Cognitive emotion regulation predictors of marital satisfaction, but they are not infertile couples $22 / 6 \%$ lifestyle percent of infertile couples in marital satisfaction once the first and $4.7 \%$ of cognitive emotion regulation infertile couples to predict marital satisfaction and beta coefficient for fertile couples lifestyle is $0 / 420$. This means that for every one unit increase in lifestyle, to increase $0 / 420$ in marital satisfaction. Beta coefficient infertile couples lifestyle is $0 / 476$. Which means that for every one unit increase in lifestyle, increased 0/476 in marital satisfaction. Beta coefficient of cognitive emotion regulation is $-0 / 222$, that for every one unit increase in marital satisfaction, decreases $0 / 222$ in cognitive emotion regulation. The results showed that cognitive emotion regulation is significant differences between women and men fertile. This finding is consistent with results Gibson (2000) and Andrews (1993) aligned. He concluded that: More than $11 \%$ of women as soon as they understand their fertility are grip, decreases their confidence. At the same time, one of the reasons for infertility in women is stress the role of motherhood. In most societies as the most important role of women is sensitive to adulthood. Also, a lot of tests and infertility treatments are done on women, increasing the psychological pressure is higher. These factors can make women infertile, to know more responsible for infertility. So infertility as a source of stress on marital functioning, sexual and affect quality of life and reduce them. In general, women are more affected by any stress and marital satisfaction and more health affected. In general, the results showed that infertile couples inappropriate use of cognitive emotion regulation and therefore have lower marital satisfaction. They fertile couple's lifestyle is more accurate predictor of marital satisfaction. Based on the results presented below are practical recommendations. Training cognitive emotion regulation strategies to infertile couples, lifestyle training to deal with stress related to infertility problems, life style education for all couples because the lifestyle is a strong predictor of marital satisfaction. 


\section{References}

Abolgaasemi, A., Shibani, H., Narimani, M., \& Gangi, M. (2008). The relationship Bing Androgynous and neuroticism with quality of life between fertile and infertile women. Women's Studies, 21, 11-12. Persian

Ahmadi, Kh., \& Fathi, A. (2007). The relationship between religious restrictions and marital adjustment. Family Research Quarterly, 5.

Ahmadi, K., Nabipoor, S. M., Kimiaee, S. A., \& Afzali, M. H. (2013). Effect of family problem-solving on marital satisfaction. Journal Of Applied Science, 11(2), 122-122.

Andrews, F. M., \& Abbey, A. (1993). Halman LJ. Is infertility-problem stress different? The dynamics of stress in fertile and infertile couples. Fertil Steril 1333 Feb; 13(2), 122-3.

Bagarvarzi, D. (2007). Increasing intimacy in marriage. Translated by Hamid et al., Isfahan, Khorasgan Islamic Azad University.

Bernstein, F. G., \& Bernstein, M. T. (2003). Marriage communication behavioral therapy from the perspective of poor translations and Secretary. Nai Abadi, Tehran Roshd emissions.

Citrate, V. (2002). Human making of Family Psychology (updated Birishk) third edition Tehran, Roshd Publication

Ellis, A., Sijel, J., Picher, J., \& Bhatia, R. (1997) .Couples therapy (translated by Saleh Yazdi). Thran: Misagh.

Etemadi, O. (2007). Increasing marital intimacy. New Journal of Psychotherapy, 13.

Fazeli, M. (2002). Consume and life style. Qom, Sobheh Sadegh.

Fisher, T. D., \& McNulty, J. K. (2012). Neuroticism and marital satisfaction: the mediating role played by the sexual relationship. Journal Family Psycholoy. 22(1), 112-22.

Fazel, G. H. (2012). Religious lifestyle and its role in youth work, psychology and religion Journal. Issue Four, winter: 74-61.

Kavyani, M. (2011). About Islamic lifestyle and happiness in life satisfaction of students in Isfahan. Journal of Psychology and religion. 4, 74-61 winter.

Kavyani, M. (2011). Quantification and measurement Islamic lifestyle. Psychology and Religion, 4(2), 27 and 44.

Khamse, A. (2010). New therapy strategies Tehran: Venerable.

Kormi, N. R. (2011). Psycho-social aspect of Infertility. Reprod Infertil J, 1(2), 58-68.

Gladding, S. (2008). Family Therapy: History, Theory and Application translator Bahari,F. Tehran: Catharsis

Lali, M., Abedi, A., \& Kajbaf, M. B. (2011), Construction and Validation Life Style Questionnaire (LSQ). psychological research, 15(1).

Halford, K. (2006). Short-term couples therapy, "helping couples to help themselves". Translate Text in Tabriz, Tehran: meta-psychology.

Hashemi Gulshan-Abadi, S. (2008). Effects of Conflict Resolution on marital satisfaction of married women and men in Tehran, Islamic Azad University undergraduate thesis, Central Tehran Branch.

Miller, Sh, \& et al (2008), marital communication skills to talk and listen to each other, the translation of Bahari,F. Tehran: Roshd.

Mohammadi, F., \& Bahrami. (2007). Stress and coping strategies in infertile women referring to Alzahra Hospital, MSc thesis, University of Medical Sciences.

Moradi, F. (2008). The relationship between personality characteristics and marital satisfaction. MA thesis not prints, Islamic Azad University Branch.

Olia, N., \& Fatehizadeh, M. (2007). The effect of education on increasing intimacy in couples marital enrichment. Journal of Family Research.

Olia, N., Fatehi, M., \& Bahrami, F. (2003). Education, marital enrichment.T: Publications Page 172, Danzheh.

Sanaei, B., Alaghebandan, S., \& Hooman, A. (2001). Haas scale family structure and marriage. Tehran, publisher of mission.

Salehi, A., Baghban, A., Bahrami, F., \& Ahmed, A. (2011). Evaluate the effectiveness of teaching emotion regulation strategies on the basis of research Issue 5 dialectical therapy, and the grass in the treatment of emotional problems dissertations, $\mathrm{PhD}$ in Counseling. 
Sanaee, Z, \& Bagherian, Z. (2004). Study on marital satisfaction of women and men in divorce Isfahan. Journal of research in psychology, 78, 15-61.

Soleimanian, A. (1995). The ideas of irrational approach based on marital satisfaction and cognitive psychology proper task of promoting proper task of promoting Tehran's Teacher Training and Educational Sciences. M. A Thesis.

Shamloo, S. (2003) .Schools and theory in personality psychology, seventh edition, Tehran: Roshd.

Sholtez, S. (2006). Personality theories. Translation Syed Yahya Syed Mohammad. Tehran, Press Publishing.

Toghyani, M., \& Et al. (2013). Islamic lifestyle with effective attitudes of university students of Islamic Azad University, Branch, Isfahan.

Vahidi, S., Ardalan A., \& Mohammad, K. (2011). The epidemiology of primary infertility in the Islamic Republic of Iran in 2111. J Reprod Infertile 2111, 2(3), 213-211(Persian).

\section{Copyrights}

Copyright for this article is retained by the author(s), with first publication rights granted to the journal.

This is an open-access article distributed under the terms and conditions of the Creative Commons Attribution license (http://creativecommons.org/licenses/by/4.0/). 